\title{
AVALIAÇÃo DE GÉIS OBTIDOS A PARTIR DA ACETILAÇÃO DA QUITOSANA EM MEIO HETEROGÊNEO
}

\author{
Rosangela Balaban Garcia*, Dayse Luzia Pinheiro da Silva e Marta Costa \\ Departamento de Química, Universidade Federal do Rio Grande do Norte, CP 1662, 59078-970 Natal - RN, Brasil \\ Fernanda Nervo Raffin
}

Departamento de Tecnologia Farmacêutica e de Alimentos, Centro de Ciências da Saúde, Universidade Federal do Rio Grande do Norte, 59078-970 Natal - RN, Brasil

Naira Machado da Silva Ruiz

Centro de Pesquisa Leopoldo A. Miguez de Mello, CENPES, Ilha do Fundão, Quadra 7, Cidade Universitária, Rio de Janeiro RJ, Brasil

Recebido em 25/10/06; aceito em 24/8/07; publicado na web em 19/12/07

\begin{abstract}
EVALUATION OF GELS OBTAINED FROM ACETYLATION OF CHITOSAN IN HETEROGENEOUS MEDIUM. Chitosan was acetylated during 2, 5 and $10 \mathrm{~h}$ and physical gels were obtained at different polymer concentrations in N,N-dimethylacetamide containing $5 \%$ of $\mathrm{LiCl}$. Acetylation was confirmed by infrared spectroscopy and ${ }^{13} \mathrm{C} \mathrm{NMR}$, and degrees of acetylation in the range of 0.82-0.91 were determined by NMR. The O-acetylation degree (0.12-0.15) was exclusively determined by a volumetric method. Rheological studies showed that the storage modulus values were smaller for the more acetylated samples and increased with the temperature and the polymer concentration. All the gels presented storage modulus superior to loss modulus, evidencing more elastic than viscous characteristics. The results obtained in this work suggest a gelation process based on a balance between $\mathrm{O}$ and $\mathrm{N}$-acetylation and intermolecular bonds.
\end{abstract}

Keywords: chitosan; gel; rheology.

\section{INTRODUÇÃO}

Em geral, os polissacarídeos são biocompatíveis, biodegradáveis e abundantes, e apresentam numerosas aplicações comerciais devido a sua ampla variedade de propriedades funcionais, que são efetivas em níveis muito baixos de concentração ${ }^{1}$. Além disso, a presença de vários grupos funcionais reativos ao longo da cadeia polimérica favorece interações com outras espécies moleculares, tanto dissolvidas quanto dispersas, podendo ocorrer ligação, quelação, complexação, microencapsulação, emulsificação, floculação, estabilização ou suspensão. Os glicanos também podem atuar como adsorventes, carreadores, suportes hidrofílicos, agentes trocadores de íons, formadores de filmes e de géis².

A quitosana ${ }^{3,4}$ é um polissacarídeo encontrado em alguns microorganismos, mas que usualmente é obtido a partir da desacetilação da quitina em meio alcalino. Sua estrutura química é constituída de unidades de 2-amino-2-desoxi-D-glicopiranose e 2acetamida-2-desoxi-D-glicopiranose interligadas por ligações glicosídicas $\beta-(1 \rightarrow 4)$. Em função da sua biodegradabilidade e biocompatibilidade, esse polímero tem sido estudado extensivamente como excipiente em várias formulações farmacêuticas, sob a forma de comprimidos, micro e nanopartículas, microesferas, granulados, lipossomas, géis e hidrogéis ${ }^{5-9}$. Esses produtos aplicados pelas vias parenteral, transdérmica, oral, vaginal, nasal, ocular, além da terapia gênica, tornam a quitosana um polímero versátil no desenvolvimento de sistemas de liberação controlada de fármacos ${ }^{10,11}$, sendo que o resultado final depende do comprimento da cadeia, densidade de carga e distribuição dessas cargas no polissacarídeo ${ }^{7}$. Foi sugerido, inclusive, que grande parte dessas aplicações utilizando a quitosana se deve ao seu mecanismo de ação, que seria uma combinação de mucoadesão e um efeito sobre a

*e-mail: balaban@digi.com.br zonula occludens ("tight junctions") intercelular, levando a um aumento da permeabilidade a diversos fármacos ${ }^{7}$, o que possibilita à quitosana atuar como cicatrizante e gastroprotetor. A zonula occludens, também conhecida como "junção oclusiva", consiste na junção intercelular composta por uma série de fusões da membrana de duas células adjacentes, formando uma barreira seletiva a pequenas moléculas e total para moléculas maiores. Essas junções consistem de proteínas (claudina e ocludina) ancoradas nas membranas de duas células adjacentes, interagindo para mantê-las juntas e evitar a passagem de moléculas entre elas. Essas conexões entre células epiteliais e endoteliais de diversos tecidos formam uma barreira natural que regula seletivamente a passagem de moléculas através de sinais intra e extracelulares.

Alguns estudos mostram várias outras aplicações para a quitosana, como agente hemostático, hipocolesterolêmico, hipouricêmico, adjuvante imunológico, bacteriostático e fungistático ${ }^{3,4,7,12,13}$.

Reações de modificação química da quitosana, como desacetilação ${ }^{14}$, $\mathrm{N}$-acetilação ${ }^{15-18}$, acilação ${ }^{19}, \mathrm{O}$-acetilação ${ }^{20}, \mathrm{O}-$ e N-ftalação ${ }^{21}, \mathrm{O}-$ carboximetilação ${ }^{21}$, oxidação ${ }^{22}$, entre outras, têm sido estudadas, de forma a preparar produtos com características específicas para determinadas aplicações. De acordo com várias estratégias químicas, um grande número de pesquisas tem sido realizado, principalmente na área farmacêutica, visando o desenvolvimento de diversas formulações ${ }^{8,9,23,24}$. Contudo, devido às fortes interações intermoleculares e ao caráter semicristalino, a quitosana é menos acessível a reagentes químicos que a celulose ${ }^{25}$.

As propriedades dos produtos obtidos por uma modificação química podem ser diferentes em função de a reação ocorrer em meio homogêneo ou heterogêneo, mesmo quando todas as demais condições reacionais são mantidas constantes. Normalmente, as reações dos polímeros semicristalinos em meio heterogêneo ocorrem preferencialmente nas porções amorfas ${ }^{26}$. Nesses casos, os pro- 
dutos da reação apresentam geralmente certa heterogeneidade ao longo da cadeia polimérica.

Nos últimos anos, a preparação de derivados de quitosana em meio homogêneo tem sido enfatizada com a justificativa de se controlar melhor a reação e de se alcançar estruturas químicas mais uniformes ${ }^{25}$. Através da acetilação da quitosana em meio homogêneo, têm sido obtidos tanto produtos solúveis em água ${ }^{25}$ quanto géis ${ }^{27-30}$, dependendo do grau de acetilação e das condições de preparação do produto. Em ambos os casos, tem sido considerado que a reação de substituição ocorre no grupamento amina ${ }^{25,27-30}$. Por sua vez, poucas informações são encontradas na literatura sobre as propriedades dos produtos de acetilação da quitosana em meio heterogêneo.

Neste trabalho, amostras de quitosana com grau de acetilação médio $17 \%$ foram reacetiladas em meio heterogêneo utilizando anidrido acético e piridina. Através da solubilização dos produtos obtidos em DMA/LiCl, foram obtidos géis que apresentaram alta estabilidade mecânica em diferentes condições de tensão, frequiência e temperatura, mesmo após lavagens com água destilada e a concentrações tão baixas quanto $2 \mathrm{~g} / \mathrm{L}$. As propriedades desses géis foram discutidas e comparadas às anteriormente divulgadas para os géis físicos de quitosana obtidos em meio homogêneo.

\section{PARTE EXPERIMENTAL}

\section{Reagentes}

Foram utilizados os seguintes reagentes para o desenvolvimento deste trabalho: N,N-dimetilformamida P.A. (Nuclear); anidrido acético P.A. (Nuclear); piridina P.A. (Nuclear); metanol P.A. (Nuclear); N,N-dimetilacetamida P.A. (Vetec Química Fina Ltda); cloreto de lítio P.A. (Nuclear); ácido acético P.A. (Vetec Química Fina Ltda); álcool etílico P.A. (Vetec Química Fina Ltda); hidróxido de sódio P.A. (Vetec Química Fina Ltda); fenolftaleína (Vetec Química Fina Ltda); ácido clorídrico P.A. (Nuclear).

\section{Polímero}

A quitosana utilizada foi fornecida pela Polymar S.A. O polímero foi purificado e caracterizado quanto ao grau de $\mathrm{N}$-acetilação (17\%) e massa molar viscosimétrica média $\left(9,2 \times 10^{5} \mathrm{~g} / \mathrm{mol}\right)$, utilizando os procedimentos descritos em trabalhos anteriores ${ }^{31}$.

\section{Métodos}

\section{Purificação da quitosana}

Antes de iniciar as reações, a quitosana foi purificada, utilizando-se os procedimentos ${ }^{32}$ descritos a seguir.

As amostras foram dissolvidas em ácido acético 0,50 mol/L, sob agitação constante, durante $12 \mathrm{~h}$. As soluções obtidas foram filtradas em funil de vidro sinterizado no 03 e membrana Millipore de acetato de celulose, de tamanhos de poro 3, 0,8 e 0,45 $\mu \mathrm{m}$ e, em seguida, neutralizadas até $\mathrm{pH}$ de aproximadamente 8,5, com NaOH $2,5 \mathrm{~mol} / \mathrm{L}$. Os polímeros precipitados foram lavados exaustivamente com água destilada, até se obter condutividade em torno de $20 \mu \mathrm{S}$. Posteriormente, foram feitas lavagens com misturas de águametanol nas proporções de 50/50, 30/70 e 0/100. O polímero final foi submetido à secagem sob pressão reduzida.

\section{Reações de acetilação}

Cerca de $25 \mathrm{~g}$ de quitosana foram colocados em um balão de fundo redondo. Em seguida, $200 \mathrm{~mL}$ de N,N-dimetilformamida (DMF) foram adicionados, com a finalidade de deixar a quitosana intumescida e, assim, favorecer a reação pela maior exposição dos grupos funcionais reativos, uma vez que a reação ocorre em meio heterogêneo. Esse contato foi mantido durante $30 \mathrm{~min}$, sob agitação constante. Posteriormente, o balão foi colocado em um banho de gelo e $1000 \mathrm{~mL}$ de uma solução previamente preparada de anidrido acético e piridina, em uma proporção de 96 e 4\% (v/v), respectivamente, foi adicionada. A mistura foi mantida sob agitação constante e as reações transcorreram durante 2,5 e 10 h, à temperatura ambiente. Após esse período, as reações foram interrompidas pela adição de água destilada e gelo. O produto insolúvel no meio foi filtrado e lavado com água destilada e, posteriormente, com metanol. O material foi secado sob pressão reduzida.

\section{Testes de solubilidade}

Cerca de $50 \mathrm{mg}$ de cada amostra foram pesadas e, em seguida, $10 \mathrm{~mL}$ de diferentes solventes (água destilada, N,N-dimetilacetamida (DMA), DMA com 5\% de $\mathrm{LiCl}$ e ácido acético a $2 \%$ ) foram adicionados. As misturas foram mantidas sob agitação constante $(\approx 300$ rpm) à temperatura ambiente e a solubilidade foi analisada após 24 e 48 h, considerando-se a massa residual de sólido após centrifugação e a formação de gel ${ }^{33,34}$.

\section{Caracterização estrutural das amostras}

\section{Análise por espectroscopia na região do infravermelho}

A caracterização estrutural das amostras foi realizada através de um espectrofotômetro de infravermelho da Bomen, modelo ABB, Série MB 104, utilizando pastilhas de KBr.

\section{Ressonância magnética nuclear de ${ }^{13} \mathrm{C}$}

Os espectros de RMN de ${ }^{13} \mathrm{C}$ foram obtidos em espectrômetro Varian Inova-300, equipado com sonda para amostras sólidas (MAS - rotação no ângulo mágico) em rotor de $7 \mathrm{~mm}$, na freqüência de 75,4 MHz. Os espectros foram obtidos utilizando a técnica de CP/ MAS (polarização cruzada com rotação no ângulo mágico) nas seguintes condições: tempo de contato de $500 \mu$ s, pulso de 90 graus $(4,5 \mu \mathrm{s})$, intervalo entre pulsos de $1 \mathrm{~s}$ e potência de pulsos de ${ }^{13} \mathrm{C}$ calibrados para atingir a condição de Hartmann-Hahn; velocidade de rotação no MAS de 4,5 KHz e 2048 transientes. Os espectros foram processados utilizando-se função de alargamento de linha ("line broadening") de $50 \mathrm{~Hz}$ e os deslocamentos químicos referenciados pelo hexametilbenzeno (pico da metila a 17,3 ppm).

\section{Determinação do grau de acetilação}

\section{Método volumétrico}

A determinação do teor de grupos $\mathrm{O}$-acetil nos produtos obtidos foi feita segundo a norma ASTM D871-72 ("American Society for Testing and Materials"), como descrito a seguir. Após a secagem por $2 \mathrm{~h}$ em estufa, a $105^{\circ} \mathrm{C}$, cada amostra foi esfriada em dessecador à temperatura ambiente e transferida para um erlenmeyer, onde se adicionou álcool etílico a $75 \%$, na proporção de $50 \mathrm{~mL}$ de álcool (75\%) para cada $1 \mathrm{~g}$ de amostra. Em seguida, foram adicionados 40 $\mathrm{mL}$ de hidróxido de sódio $(\mathrm{NaOH})$ 0,5 $\mathrm{mol} / \mathrm{L}$. O recipiente foi vedado e mantido por cinco dias à temperatura ambiente, com agitações ocasionais. Decorrido esse período, a quantidade de $\mathrm{NaOH}$ não consumido foi determinada por titulação com ácido clorídrico $(\mathrm{HCl})$ 0,2 $\mathrm{mol} / \mathrm{L}$, utilizando como indicador fenolftaleína. A determinação do teor de acetato foi feita através da Equação 1

$$
\% \text { acetato }=\frac{\left(V_{\text {Branco }}-V_{\text {Amostra }}\right) \times M_{H C l} \times 0,043 \times 100}{m_{\text {Amostra }}}
$$

onde: $V_{\text {Branco }}$ corresponde ao volume de ácido para a dosagem do 
branco; $V_{\text {Amostra }}$ é o volume do ácido para dosagem da amostra; $M_{H C l}$ é a concentração da solução de $\mathrm{HCl}$ dada em mol/L e $m_{\text {Amostra }}$ é a massa em grama da amostra utilizada.

Utilizando a Equação 2, determinou-se o grau de substituição $(G S)$. As análises foram feitas em triplicata.

$$
G S=\frac{181 \times(\% \text { acetato })}{4300-42 \times(\% \text { acetato })}
$$

\section{Preparação do gel}

Quantidades pré-definidas das amostras de quitosana acetilada foram cuidadosamente pesadas e adicionadas a uma solução de $\mathrm{N}, \mathrm{N}$-dimetilacetamida (DMA) contendo $5 \%$ de $\mathrm{LiCl}$, de forma que se obtivessem ao final concentrações de quitosana de 2,5 ou $10 \mathrm{~g} /$ L. A mistura foi submetida à agitação constante de $300 \mathrm{rpm}$ durante $48 \mathrm{~h}$, à temperatura ambiente, e mantida em repouso, também à temperatura ambiente, por $24 \mathrm{~h}$, período suficiente para estabilizar o fenômeno de sinerese.

\section{Lavagem do gel}

Uma vez que o DMA é um solvente orgânico com elevado grau de toxicidade, é importante que seja eliminado completamente do gel, caso se pretenda alcançar aplicações biomédicas. Para tanto, preparou-se um volume de $10 \mathrm{~mL}$ de gel, com uma quantidade de DMA cuidadosamente calculada e corrigida, e deixou-se o gel imerso em $1 \mathrm{~L}$ de água destilada, que foi sendo renovada a cada saturação. O equilíbrio de difusão do DMA, do gel para o meio aquoso, foi determinado por espectrofotometria na região do ultravioleta, utilizando o espectrofotômetro Cary $1 \mathrm{E}$ - Varian.

\section{Caracterização reológica}

Os géis contendo DMA/LiCl 5\% e os submetidos a lavagens foram analisados em reômetro ReoStress R150 - Haake, com sensores do tipo cone-placa. A região de viscoelasticidade linear foi cuidadosamente determinada e, a partir daí, pôde-se analisar os módulos de estocagem (G') e de perda (G") das amostras em função da tensão $(0,1$ a $20 \mathrm{~Pa})$, da frequiência $(0,1 \mathrm{a} 100 \mathrm{~Hz})$, do tempo (0 a $30 \mathrm{~min})$ e da temperatura $\left(20\right.$ a $\left.80{ }^{\circ} \mathrm{C}\right)$. Esse estudo foi realizado em triplicata para cada amostra, de forma a verificar a sua reprodutibilidade.

\section{RESULTADOS E DISCUSSÃO}

\section{Testes de solubilidade}

A Tabela 1 mostra os resultados dos testes de solubilidade para a quitosana e os seus produtos derivados da acetilação.

Observa-se que as amostras de quitosana acetiladas apresentam menor afinidade pelos solventes mais polares e próticos (água e solução aquosa de ácido acético a 2\%), não alcançando solubilidade. Esse resultado pode ser um reflexo da diminuição do número de grupos hidrofílicos $\left(-\mathrm{OH}\right.$ e $\left.-\mathrm{NH}_{2}\right)$ livres do polímero. Além disso, a reação de acetilação, por ter se processado em meio heterogêneo, provavelmente ocorreu nos domínios amorfos, preservando as regiões cristalinas e favorecendo o surgimento dos grupos acetil em uma distribuição pouco aleatória na cadeia polimérica. Sabe-se que a obtenção de derivados acetilados de quitosana solúveis em água se deve a uma distribuição aleatória dos grupos acetil proporcionada pela reação em solução ${ }^{16,35,36}$. Nessas circunstâncias, até cerca de $50 \%$ de grau de acetilação, a inserção de grupos acetil hidrofóbicos na macromolécula diminui as atrações entre as cadeias poliméricas via ligações hidrogênio, facilitando a solubilização do polímero, independente do $\mathrm{pH}$ do meio. Por outro lado, se a distribuição dos grupos acetil na cadeia polimérica for seqüenciada, ou seja, se houver a tendência de formação de unidades acetiladas em bloco, as interações hidrofóbicas entre esses segmentos, juntamente com as ligações hidrogênio entre os grupos $\mathrm{OH}$ e $\mathrm{NH}_{2}$, podem intensificar as interações entre as cadeias poliméricas, dificultando a solubilização do polímero.

Foi investigada, também, a solubilidade das amostras em DMA sem contribuição de força iônica ( $\mathrm{LiCl})$. A parcial solubilidade em DMA das amostras acetiladas concorda com a hipótese dos polímeros acetilados apresentarem forças de atração intermoleculares menos intensas que a quitosana original.

A formação de géis firmes e transparentes para as amostras de quitosana acetilada, na presença de DMA com $5 \%$ de $\mathrm{LiCl}$, mostra a importância da força iônica no meio. $\mathrm{O} \mathrm{LiCl}$ foi, dessa forma, responsável pela ruptura das regiões cristalinas. Isso pode ser explicado pelo fato do $\mathrm{Li}^{+}$formar um complexo com as moléculas do DMA, originando um macrocátion ([DMA+Li $\left.]^{+}\right)$, e os íons cloreto, por sua vez, passam a formar ligações semelhantes às ligações hidrogênio com os átomos de hidrogênio das hidroxilas do polissacarídeo, promovendo a redução das interações entre as moléculas de quitosana e a conseqüente solubilização do polímero ${ }^{37}$. Após a solubilização total do polímero e repouso da solução, a presença provável de blocos de unidades de glucosamina não acetiladas possibilitou interações intermoleculares ainda significativamente fortes, formando zonas de junção por ligações hidrogênio. Deve-se também considerar a hipótese da presença de blocos de unidades de glucosamina acetiladas, que poderiam adicionalmente promover significativas interações intermoleculares hidrofóbicas. Porém, todas essas interações foram sendo estabelecidas de uma forma gradual, após a solução ser mantida em repouso por um tempo mínimo de $24 \mathrm{~h}$. A sinerese observada até $48 \mathrm{~h}$ após o gel ter sido formado, com redução de massa em torno de $20 \%$, é um forte indício de aumento das interações nas zonas de junção. Foi verificado que, após $48 \mathrm{~h}$ do gel formado, a sua massa foi mantida constante.

Quitosana N-acetilada solúvel em DMA com 5\% de LiCl sem

Tabela 1. Solubilidade da quitosana e das amostras acetiladas

\begin{tabular}{|c|c|c|c|c|c|c|c|c|}
\hline \multirow[t]{3}{*}{ Quitosana } & & & \multicolumn{6}{|c|}{ Quitosana acetilada } \\
\hline & & & \multicolumn{6}{|c|}{ Tempo de reação (h) } \\
\hline & & & \multicolumn{2}{|c|}{2} & \multicolumn{2}{|c|}{5} & \multicolumn{2}{|c|}{10} \\
\hline Tempo de agitação (h) & 24 & 48 & 24 & 48 & 24 & 48 & 24 & 48 \\
\hline $\mathrm{DMA} / 5 \% \mathrm{LiCl}$ & - & - & \pm & $\mathrm{g}$ & \pm & $\mathrm{g}$ & \pm & $\mathrm{g}$ \\
\hline DMA & - & - & \pm & $\begin{array}{l}8 \\
\pm\end{array}$ & \pm & \pm & \pm & $\begin{array}{l}0 \\
\pm\end{array}$ \\
\hline Ácido acético $2 \%$ & + & + & - & - & - & - & - & - \\
\hline Água & - & - & - & - & - & - & - & - \\
\hline
\end{tabular}

(-) Insolúvel; (+) Solúvel; () Solubilidade parcial; (g) Formação de gel. 
ocorrência de gelificação tem sido obtida através de condições reacionais homogêneas ${ }^{38}$. Esse dado, juntamente com os resultados mostrados acima, está de acordo com a hipótese apresentada neste trabalho que a presença de blocos acetilados e desacetilados é, de fato, necessária para a formação da estrutura tridimensional do gel, por intermédio das interações intermoleculares hidrofóbicas e por ligações hidrogênio, respectivamente.

\section{Caracterização estrutural}

\section{Espectrofotometria na região do infravermelho}

As principais absorções características da quitosana são observadas nas faixas de $3600-3200 \mathrm{~cm}^{-1}$, que correspondem à deformação axial dos grupos hidroxila e amino livre; $1690-1650 \mathrm{~cm}^{-1}$, relacionada à deformação axial $\mathrm{C}=\mathrm{O}$ de amidas e $1640-1540 \mathrm{~cm}^{-1}$, devido à deformação angular do grupo $\mathrm{NH}$ de amina ${ }^{39,40}$. A comprovação da acetilação foi realizada pelo acompanhamento da intensidade relativa das bandas (Tabela 2) a $1650 \mathrm{~cm}^{-1}(\mathrm{C}=\mathrm{O}$ de amida) e a $1550 \mathrm{~cm}^{-1}$ (NH de amina). Além disso, foi acompanhado o aparecimento de uma banda a $1750 \mathrm{~cm}^{-1}$ nas amostras acetiladas, que corresponde à deformação axial $\mathrm{C}=\mathrm{O}$ de éster. $\mathrm{O}$ aumento de intensidade das bandas de carbonila de amida e de éster com o tempo de reação sugere que a reação possibilitou a acetilação, não somente dos grupos amino livres, mas também dos grupamentos hidroxílicos, embora os grupos $\mathrm{NH}_{2}$ sejam muito mais reativos que esses últimos. A O-acetilação pode ser explicada pelo fato de possíveis quantidades significativas de unidades glicosídicas com grupamentos amino livres fazerem parte das regiões cristalinas do polímero. Como a reação de acetilação se processou em meio heterogêneo, provavelmente, somente as regiões amorfas foram acetiladas. Dessa forma, em termos relativos, os grupos $\mathrm{OH}$ tornaram-se mais susceptíveis à reação, devido à menor exposição dos grupos $\mathrm{NH}_{2}$, crescendo assim a probabilidade dos grupos acetila reagirem com os grupamentos hidroxila.

Foi observado, também, um aumento significativo na intensidade da banda a $1340 \mathrm{~cm}^{-1}$ com o aumento do tempo de reação. Essa banda foi atribuída à deformação angular do $\mathrm{CH}_{3}$, correspondente à metila de amida e/ou de éster.

Tabela 2. Razões $\mathrm{A}_{\mathrm{CO}(\text { amida) }} / \mathrm{A}_{\mathrm{OH}}, \mathrm{A}_{\mathrm{CO}(\text { éster })} / \mathrm{A}_{\mathrm{OH}}$ e $\mathrm{A}_{\mathrm{NH}(\text { amina) }} / \mathrm{A}_{\mathrm{OH}}$ para a quitosana e seus derivados acetilados (QA2, QA5 e QA10= quitosana acetilada por 2,5 e $10 \mathrm{~h}$, respectivamente)

\begin{tabular}{lccc}
\hline AMOSTRA & $\mathrm{A}_{\mathrm{CO}(\text { amida) }} / \mathrm{A}_{\mathrm{OH}}$ & $\mathrm{A}_{\mathrm{CO}(\text { éster })} / \mathrm{A}_{\mathrm{OH}}$ & $\mathrm{A}_{\mathrm{NH}(\text { (amina) }} / \mathrm{A}_{\mathrm{OH}}$ \\
\hline Quitosana & 0,80 & 0 & 0,84 \\
QA2 & 0,81 & 0,54 & 0,74 \\
QA5 & 0,85 & 0,73 & 0,68 \\
QA10 & 0,86 & 0,83 & 0,54 \\
\hline
\end{tabular}

Uma análise semiquantitativa dos graus de O- e N-acetilação pôde ser feita a partir dos dados dos espectros obtidos. De acordo com o método da linha base ${ }^{40,41}$, toma-se a banda de $\mathrm{OH}\left(3400 \mathrm{~cm}^{-1}\right)$ como padrão de referência interno. As razões de absorção entre a carbonila de éster e de amida, bem como do grupamento amino com relação ao grupo $\mathrm{OH}, \mathrm{A}_{\mathrm{C}=\mathrm{O}(\text { esser) }} / \mathrm{A}_{\mathrm{OH}}, \mathrm{A}_{\mathrm{C}=\mathrm{O}(\text { amida }} / \mathrm{A}_{\mathrm{OH}} \mathrm{e} \mathrm{A}_{\mathrm{NH}(\text { amina) }} / \mathrm{A}_{\mathrm{OH}}$, respectivamente, foram calculadas e utilizadas para quantificar o aumento da intensidade das bandas $\mathrm{C}=\mathrm{O}$ de éster $\left(1750 \mathrm{~cm}^{-1}\right)$ e $\mathrm{C}=\mathrm{O}$ de amida (1650 $\left.\mathrm{cm}^{-1}\right)$, e a diminuição da banda de $\mathrm{NH}_{2}\left(1550 \mathrm{~cm}^{-1}\right)$.

Pode-se observar, na Tabela 2, que a quitosana apresenta razões de $\mathrm{A}_{\mathrm{NH}(a m i n a)} / \mathrm{A}_{\mathrm{OH}}$ superiores às amostras modificadas quimicamente. Isso se deve à acetilação nos grupos amino livres desses últimos. Além disso, à medida que o tempo de acetilação aumentou
$(2,5$ e $10 \mathrm{~h})$, reduziu-se a razão $\mathrm{A}_{\mathrm{NH}(\text { amina) }} / \mathrm{A}_{\mathrm{OH}}$, uma vez que os grupos amino livres foram sendo consumidos. Por outro lado, a razão $\mathrm{A}_{\mathrm{C}=\mathrm{O}(\text { amida) }} / \mathrm{A}_{\mathrm{OH}}$, como era de se esperar, apresentou-se superior para as amostras submetidas à reação, confirmando a acetilação nos grupos $\mathrm{NH}_{2}$. Da mesma forma, à medida que se aumentou o tempo de reação, aumentou-se também a razão $\mathrm{A}_{\mathrm{C}=\mathrm{O}(\text { éster) }} / \mathrm{A}_{\mathrm{OH}}$.

Com relação à razão $\mathrm{A}_{\mathrm{CO}(e ́ s t e r)} / \mathrm{A}_{\mathrm{OH}}$, ela é igual a zero para a quitosana, pois esse polímero se caracteriza por apresentar apenas os grupos amino parcialmente acetilados, estando os grupamentos $\mathrm{OH}$ livres. No entanto, a O-acetilação pôde ser confirmada pelos valores da razão $\mathrm{A}_{\mathrm{CO}(e ́ s t e r)} / \mathrm{A}_{\mathrm{OH}}$ para as amostras acetiladas. $\mathrm{E}$, da mesma forma, pôde-se observar que os valores dessa razão crescem com o aumento do tempo de reação.

Ressonância magnética nuclear de ${ }^{13} \mathrm{C}$ no estado sólido (RMN $\left.{ }^{13} \mathrm{C}\right)$

A Figura 1 mostra o espectro de $\mathrm{RMN}{ }^{13} \mathrm{C}$ da quitosana não modificada e a associação dos picos aos átomos de carbono, que se encontra em concordância com os dados da literatura ${ }^{42,43}$. Os picos em torno de 24 e 175 ppm são atribuídos, respectivamente, aos grupamentos metila $\left(\mathrm{CH}_{3}\right)$ e carbonila $(\mathrm{CO})$ do resíduo da $\mathrm{N}$ acetilglicosamina $^{44}$, que estão presentes em aproximadamente $17 \%$ na quitosana original. Os demais picos associados ao carbono encontram-se indicados na Figura 1.
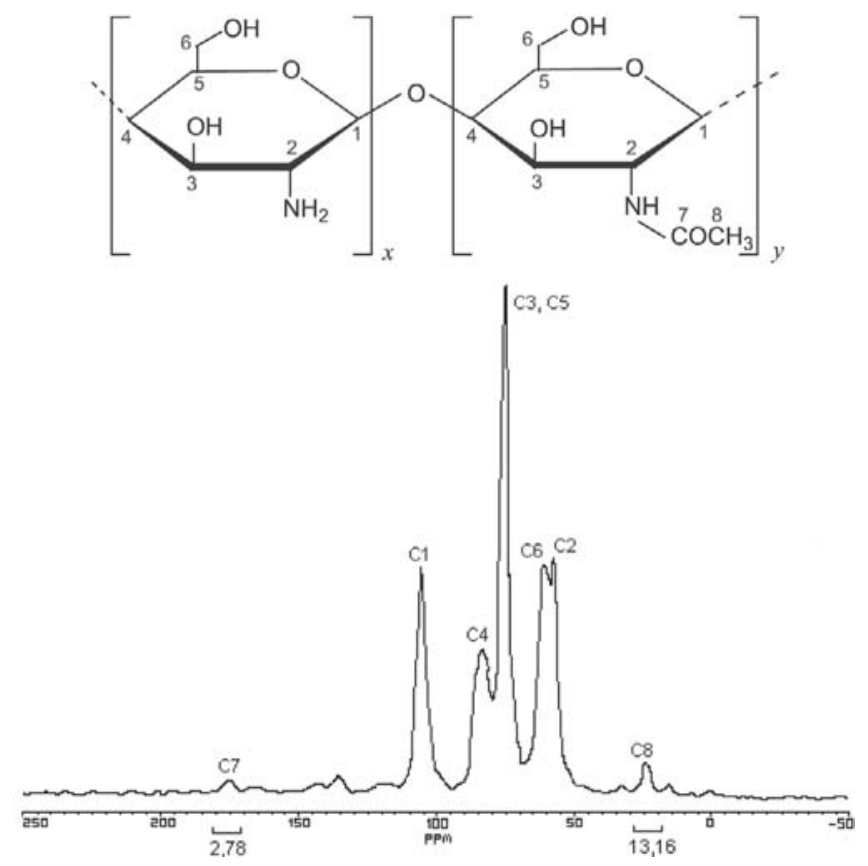

Figura 1. Espectro de $R M N^{13} C$ da quitosana não modificada

A Figura 2 apresenta os espectros de RMN ${ }^{13} \mathrm{C}$ das amostras de quitosana acetiladas por $2 \mathrm{~h}$. Assim como visto na espectroscopia por infravermelho, os espectros de $\mathrm{RMN}{ }^{13} \mathrm{C}$ das amostras acetiladas apresentaram poucas diferenças entre si. No entanto, os picos em 24 e 175 ppm (C8 e C7, respectivamente), para os três polímeros modificados, estão significativamente mais pronunciados, em comparação com a quitosana não modificada, o que confirma a acetilação nos grupamentos amino livres. Além disso, o pico a 175 ppm está associado não só ao carbono da carbonila da amida (C7), mas também ao carbono da carbonila do grupo éster (C10). Dessa forma, a quantificação isolada dos grupamentos $\mathrm{OH}$ e $\mathrm{NH}_{2}$ acetilados não foi possível através dessa técnica, devido à sobreposição dos picos dos carbonos C7 e C10.

Os sinais em torno de 230 e 110 ppm, que aparecem nos espec- 

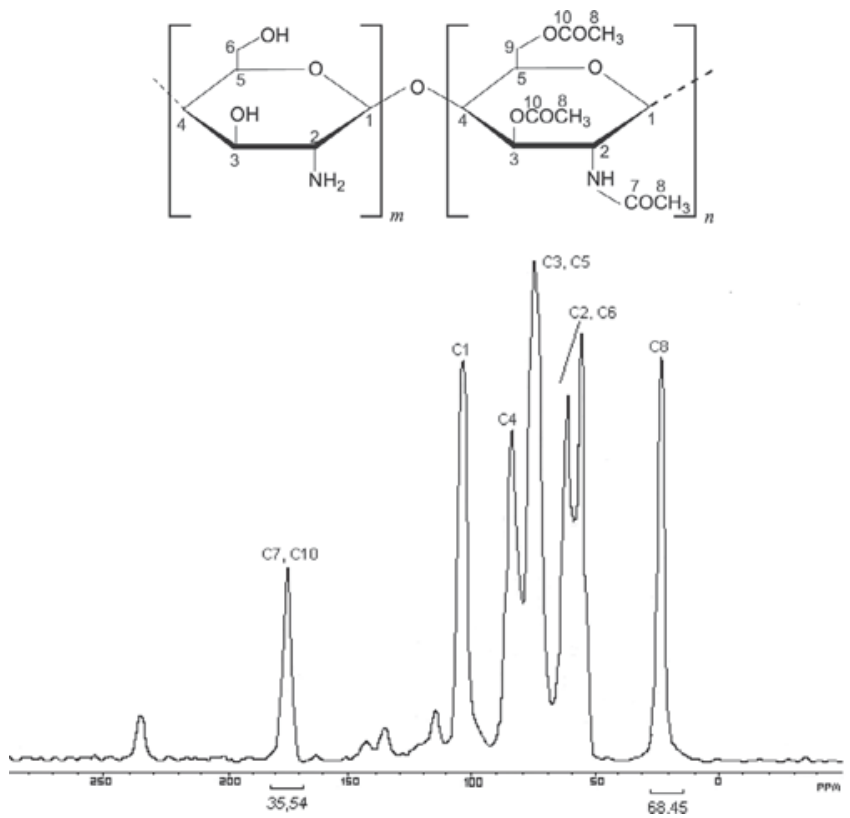

Figura 2. Espectros de $R M N^{13} C$ das amostras acetiladas durante: (a) $2 \mathrm{~h}$; (b) $5 \mathrm{~h} ; \mathrm{e}$ (c) $10 \mathrm{~h}$

tros das amostras acetiladas e estão ausentes na quitosana, são atribuídos a bandas laterais do pico a 175 ppm.

A partir da Tabela 3, pode-se perceber que todas as amostras acetiladas apresentaram uma maior porcentagem de $\mathrm{C} 7 / \mathrm{C} 10$ e $\mathrm{C} 8$ em relação à quitosana, o que é perfeitamente atribuída à acetilação ocorrida nos grupamentos hidroxila e amino livres. No entanto, essas amostras não apresentaram, praticamente, nenhuma diferença entre si. Isso sugere que a modificação química deu origem a produtos muito semelhantes estruturalmente, embora o tempo de reação tenha sido diferente.

Tabela 3. Comparação da intensidade dos picos entre a quitosana e seus derivados, por RMN ${ }^{13} \mathrm{C}$

\begin{tabular}{lcc}
\hline Amostra & \multicolumn{2}{c}{ Tipos de carbono $(\% \mathrm{~m} / \mathrm{m})$} \\
\cline { 2 - 3 } & $\mathrm{C} 7$ e $\mathrm{C} 10(175 \mathrm{ppm})$ & $\mathrm{C} 8(23 \mathrm{ppm})$ \\
\hline Quitosana & 0,5 & 2,2 \\
QA2 & 8,2 & 11,2 \\
QA5 & 8,2 & 12,0 \\
QA10 & 8,1 & 11,8 \\
\hline
\end{tabular}

Uma estimativa do grau de substituição (N- e O-acetilação) foi realizada em função da razão entre as porcentagens de carbono presentes nas amostras a $24 \mathrm{ppm}(\mathrm{C} 8)$ e a $105 \mathrm{ppm}(\mathrm{C} 1)$, sendo este último o padrão interno de referência. De acordo com a Tabela 4, pode-se verificar que as amostras acetiladas apresentaram graus de substituição entre 0,82 e 0,91 . Tendo em vista que o grau de substituição máximo seria 3 (as duas hidroxilas dos carbonos 3 e 6, e o grupo amino livre), o percentual de $\mathrm{OH}$ e $\mathrm{NH}_{2}$ acetilados variou de 27 a $30 \%$. Em trabalhos anteriores publicados por outros pesquisadores ${ }^{27-30}$, a acetilação da quitosana em meio homogêneo foi realizada pelo anidrido acético em solução aquosa contendo um álcool, alcançando graus de $\mathrm{N}$-acetilação na faixa de 25 a 99,5\%, a partir da variação da razão molar anidrido acético/grupos amino livres da quitosana. Entretanto, deve-se lembrar que, nessas condições experimentais, a acetilação ocorre apenas nos grupos amino livres ${ }^{27}$. Dessa forma, por exemplo, um grau de $\mathrm{N}$-acetilação de $99,5 \%$ corresponde a um DS de 0,995 e a um percentual global de acetilação de 33\%, se forem levadas em consideração as duas hidroxilas presentes em cada unidade glicosídica. Comparando esse dado da literatura com os resultados obtidos nesse trabalho (DA entre 27 e 30\%), pode-se considerar que as amostras estudadas apresentam grau de acetilação da mesma ordem de grandeza daquelas obtidas por acetilação em meio homogêneo. A diferença básica entre as amostras obtidas por acetilação em meio homogêneo e heterogêneo seria a distribuição dos grupos acetil ao longo da cadeia polimérica.

Tabela 4. Estimativa do grau de substituição da quitosana e seus derivados

\begin{tabular}{lc}
\hline Amostra & Grau de Substituição (GS) \\
\hline Quitosana & 0,13 \\
QA2 & 0,82 \\
QA5 & 0,89 \\
QA10 & 0,91 \\
\hline
\end{tabular}

\section{Volumetria}

$\mathrm{Na}$ tentativa de determinar o grau de O-acetilação, realizou-se também de uma caracterização volumétrica, tendo como base a norma ASTM D871-72. De acordo com a Tabela 5, é possível verificar o aumento da porcentagem em massa dos grupos O-acetil e do grau de substituição dos grupos $\mathrm{OH}$, à medida que aumentou o tempo de reação, estando esse resultado de acordo com a Tabela 4, obtida a partir de dados dos espectros de RMN ${ }^{13} \mathrm{C}$. É interessante observar que, embora as amostras acetiladas apresentem grupos $\mathrm{N}$-acetil, estes não foram quantificados pelo método volumétrico, pois se trata de um método específico para substituintes no grupo $\mathrm{OH}$. Isso é comprovado pelo resultado apresentado pela quitosana, que embora apresente grupos $\mathrm{N}$-acetila na sua estrutura, como mostrado nos resultados do infravermelho e $\mathrm{RMN}{ }^{13} \mathrm{C}$, esse grupo não foi quantificado, sendo, pois, zero o valor do grau de substituição Oacetil, como seria esperado.

Tabela 5. Determinação por método volumétrico do grau de substituição dos grupos $\mathrm{OH}$ dos derivados da quitosana

\begin{tabular}{lcc}
\hline Amostra & O-acetil $(\% \mathrm{~m} / \mathrm{m})$ & Grau de substituição $(\mathrm{GS})$ \\
\hline Quitosana & 0 & 0 \\
QA2 & 2,5 & 0,12 \\
QA5 & 3,0 & 0,13 \\
QA10 & 3,5 & 0,15 \\
\hline
\end{tabular}

Um paralelo entre o grau de substituição obtido pelo método volumétrico (Tabela 5) e o grau de substituição obtido a partir dos dados de $\mathrm{RMN}{ }^{13} \mathrm{C}$ (Tabela 4), com a finalidade de determinar o grau de $\mathrm{N}$-acetilação, não poderia ser realizado com extremo rigor, uma vez que se constituem em métodos bastante diferentes de determinação, com erros experimentais envolvidos. Entretanto, podese observar uma significativa coerência entre eles. O GS determinado por $\mathrm{RMN}{ }^{13} \mathrm{C}$ foi sempre maior que o obtido por volumetria, o que corrobora com a maior reatividade dos grupos amino livres em relação às hidroxilas.

\section{Caracterização reológica}

As análises reológicas foram realizadas em géis de quitosana acetilada. O primeiro passo, antes de se iniciar esse tipo de análise, foi encontrar parâmetros, como tensão e freqüência de cisalhamento, 
apropriados para se trabalhar dentro da região de viscoelasticidade linear, uma vez que, para comportamentos viscoelásticos não lineares, cada valor de tensão aplicada leva a uma deformação dependente do tempo, que só pode ser determinada por experimentos conduzidos naquela tensão. Por outro lado, na região linear, os módulos de estocagem (G') e de perda (G') independem da magnitude da tensão aplicada ${ }^{45}$.

Primeiramente, foi analisada a influência da tensão, da freqüência e do tempo de cisalhamento para diferentes concentrações do polímero em função do grau de acetilação. Foi observado que os géis apresentaram pouca sensibilidade à variação desses parâmetros, sendo os valores de G' praticamente constantes, o que é um indício da sua grande estabilidade.

Para todos os parâmetros analisados, o módulo de estocagem $\left(G^{\prime}\right)$ foi superior ao módulo de perda (G'), demonstrando que os materiais obtidos possuem características muito mais elásticas que viscosas.

Com relação às propriedades elásticas, as amostras cujas concentrações em polímero eram maiores apresentaram valores de G' superiores, o que pode ser atribuído ao maior número de sítios para interações intermoleculares, que são responsáveis pela reticulação física do gel. Outro dado interessante é que, embora a diferença entre os graus de acetilação seja pequena (Tabelas 4 e 5), foi suficiente para permitir a obtenção de géis com graus de rigidez diferentes. Isso mostra que os grupamentos acetila, por não serem de elevada massa molar, como os grupos acila utilizados por Hirano et $a l^{46,47}$ (com mais de seis carbonos), permitiram a formação de fortes e estáveis ligações hidrogênio nas porções não acetiladas.

Observou-se que as amostras mais acetiladas apresentaram valores de G' menores. Isso pode estar relacionado à diminuição dos grupamentos hidroxila e amino livres, os quais seriam responsáveis pela formação de zonas de junção por intermédio de ligações hidrogênio. Como as condições reacionais de acetilação utilizadas permitiram a $\mathrm{N}$ - e $\mathrm{O}$-acetilação, é provável que graus maiores de acetilação aproximem a estrutura da amostra à estrutura da quitina que, por sua vez, é solúvel nesse meio. Nessas circunstâncias, o processo de gelificação parece ser um resultado do balanço entre $\mathrm{N}$ - e O-acetilação, que influencia diretamente nas interações intermoleculares hidrofóbicas e de hidrogênio.

A remoção do DMA, pelas sucessivas lavagens com água destilada, foi comprovada por espectrofotometria na região do ultravioleta a partir de curva padrão e permitiu a obtenção de um gel mais rígido e até mais estável, provavelmente, pela formação de novas ligações hidrofóbicas e de hidrogênio, fazendo com que a estrutura do gel se contraísse de forma a reduzir seu volume, dando a ele um aspecto borrachoso.

Embora as amostras de quitosana acetilada fossem insolúveis em água, como mostrado na Tabela 1, a miscibilidade do DMA nesse meio permitiu sua difusão e, conseqüentemente, sua substituição, sem que o gel fosse desfeito, permanecendo translúcido. Isso pode ser atribuído ao aumento da exposição dos grupos $-\mathrm{NH}_{2}$ durante a gelificação, o que não foi possível durante a análise de solubilidade, devido à preservação das regiões cristalinas, uma vez que a reação de acetilação ocorreu em meio heterogêneo.

A temperatura foi o último parâmetro analisado. Pode-se observar que, para as amostras não tratadas (géis não lavados com água destilada), a temperatura apresentou uma influência muito mais expressiva que para as amostras de géis lavados. A elevação do módulo de estocagem $\left(G^{\prime}\right)$ com o aumento da temperatura pode ser atribuída à formação de novas zonas de junção, as quais, provavelmente, são de caráter endotérmico. Esse tipo de fenômeno foi estudado por Chenite et $_{\text {al }}{ }^{48} \mathrm{em}$ soluções de quitosana, cujos grupamentos amino livres foram neutralizados com fosfato de glicerol. Pôde-se obser- var que, para géis de QA5 (quitosana acetilada por 5 h) e QA10 (quitosana acetilada por $10 \mathrm{~h}$ ) não lavados, os valores de G' aumentam com a elevação da temperatura, ao contrário das amostras QA2 (quitosana acetilada por $2 \mathrm{~h}$ ). Isso pode estar relacionado com a maior rigidez que essa última possui, dificultando, assim, um rearranjo molecular. Por outro lado, os géis mais acetilados (QA5 e QA10), por possuírem maior flexibilidade, possibilitam uma maior liberdade de movimento das moléculas no seu interior, o que favorece a formação de novas zonas de junção com o aumento da temperatura. A menor sensibilidade das amostras lavadas ao aumento da temperatura pode estar relacionada à redução da mobilidade das moléculas, devido ao aumento das interações intermoleculares formadas nesse meio, e conseqüente aumento das zonas de junção ${ }^{49}$. Além disso, os géis lavados submetidos a esse tipo de análise não apresentaram nenhuma mudança no aspecto visual.

Um outro dado importante verificado foi a irreversibilidade desses géis físicos através de mudanças de $\mathrm{pH}(2-12)$, solvente (DMA/5\% de $\mathrm{LiCl}$ ) e temperatura (até $120{ }^{\circ} \mathrm{C}$ ). Isso comprova a existência de fortes e estáveis interações intermoleculares, principalmente pela provável reestruturação de regiões cristalinas, que foram responsáveis pelas fortes redes físicas do gel.

A Figura 3 mostra o processo de gelificação desses géis. É importante ressaltar a fácil moldagem dos géis preparados e a sua capacidade de conservar a forma do molde após a sinerese. Observa-se, também, a significativa redução do volume do gel após a lavagem, devido ao aumento das interações inter e intramoleculares, porém, sem aparentes precipitações do polímero no gel. No entanto, é possível verificar a translucidez do gel mesmo após a remoção do DMA.

Comparando-se as características gerais dos géis estudados nesse trabalho, que foram obtidos por acetilação em meio heterogêneo, com as dos géis obtidos por acetilação em meio homogêneo ${ }^{30}$, podese verificar que, nos dois casos, a gelificação ocorreu em resposta a uma redução da hidroficidade da quitosana pela inserção dos grupos acetil e a utilização de um meio com constante dielétrica adequada, que permitiu um equilíbrio entre as interações intermoleculares hidrofóbicas e hidrofílicas (ligações hidrogênio). Além disso, pelos dois métodos são obtidos géis com resistência mecânica bastante significativa, com o módulo de estocagem na faixa de $10^{4} \mathrm{~Pa}$, após a lavagem com água destilada, que se faz necessária nos dois procedimentos.

\section{CONCLUSÕES}

A caracterização estrutural da quitosana modificada quimicamente apresentou evidências de incorporação dos grupos acetila tanto nos grupamentos amino livres, quanto nos hidroxílicos, entretanto, a diferença em grau de substituição das amostras em função do tempo de reação foi pequena. Apesar disso, diferenças significativas foram observadas nas propriedades reológicas dos géis obtidos a partir da solubilização do polímero em DMA-5\% LiCl. Os polímeros com menor grau de acetilação formaram géis com maior módulo de estocagem, avaliados a partir de varreduras de tensão, frequiência, tempo de cisalhamento e temperatura. Esse resultado foi atribuído à diminuição dos grupamentos hidroxila e amino livres com o aumento do grau de acetilação, os quais também seriam responsáveis pelas zonas de junção formadas por intermédio de ligações hidrogênio. Todos os géis analisados, inclusive os que foram submetidos à lavagem com água destilada, apresentaram módulo de estocagem maior que o módulo de perda, indicando que esses géis apresentam comportamento elástico acentuado. A facilidade de moldagem desses géis, associada as suas propriedades reológicas sugerem um potencial de aplicabilidade em diversas áreas. 

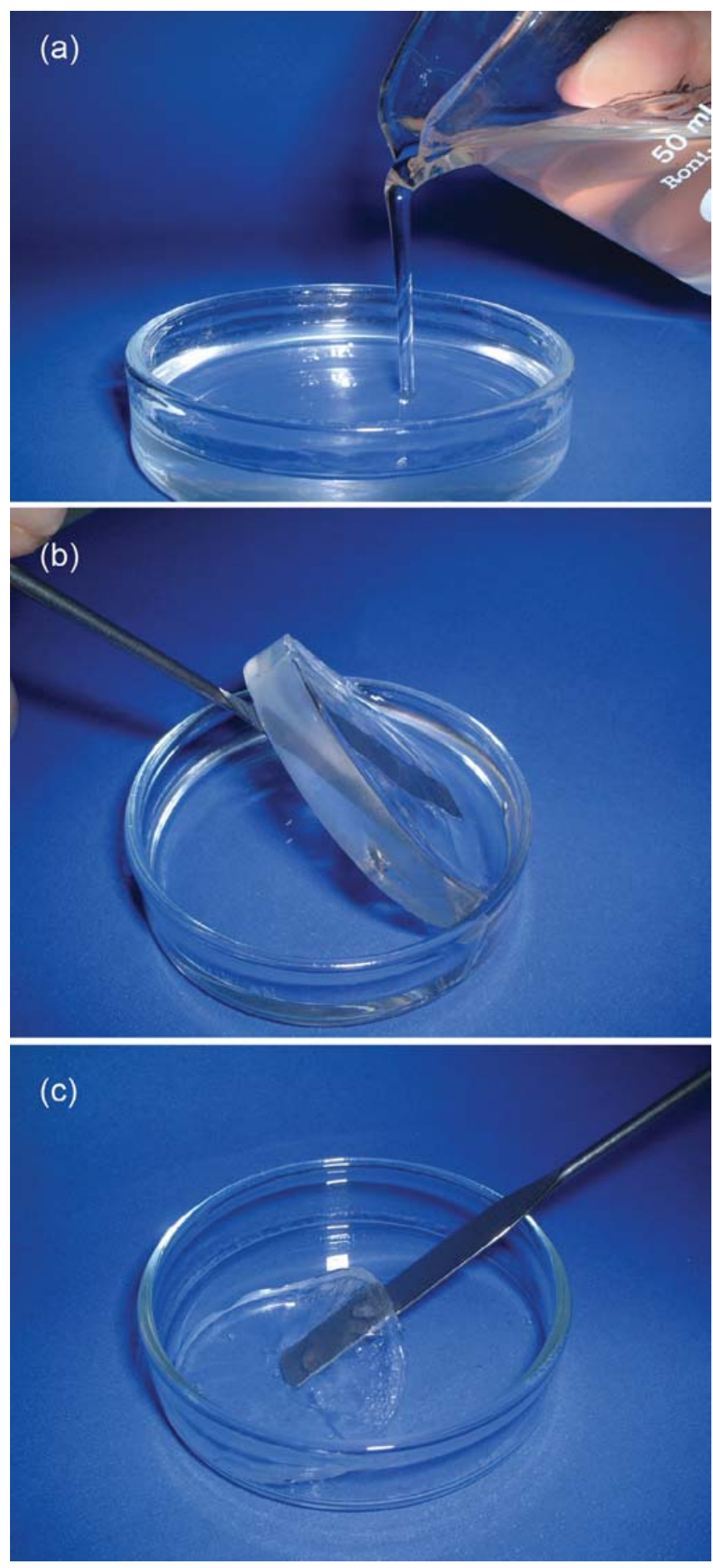

Figura 3. Gelificação da quitosana acetilada (QA5) em DMA/5\% $\mathrm{LiCl}$, à concentração de $5 \mathrm{~g} / \mathrm{L}$ do polímero: (a) solução após $24 \mathrm{~h}$ de agitação; (b) gel após 48 h de repouso; (c) gel após a lavagem em água destilada

\section{MATERIAL SUPLEMENTAR}

No material suplementar, disponível gratuitamente em http:// quimicanova.sbq.org.br, na forma de arquivo PDF, estão as figuras referentes à análise reológica dos géis em função da tensão, da frequiência, do tempo de cisalhamento e da temperatura para diferentes concentrações do polímero e graus de acetilação (Figuras $1 \mathrm{~S}$ a 9S).

\section{AGRADECIMENTOS}

À FINEP e à CAPES pelos auxílios recebidos.

\section{REFERÊNCIAS}

1. Yalpani, M.; Polysaccharide: synthesis, modifications and structure/ property relations, Elsevier: New York, 1998.

2. Chen, J.; Jo, S.; Park, K.; Carbohydr. Polym. 1995, $28,69$.

3. Muzzarelli, R. A. A.; Carbohydr. Polym. 1996, 29, 309.

4. Domard, A.; IV Pharmatech: New Perspectives in Drug Delivery System, Natal, Brasil, 1999.

5. Lee, K. Y.; Ha, W. S.; Park, W. H.; Biomaterials 1995, 16, 1211.

6. Grodzinski, J. J.; React. Funct. Polym. 1999, 39, 99.

7. Dodane, V.; Vilivalam,V. D.; Pharmaceutical Science \& Technology Today 1998, $1,246$.

8. Felt, O.; Furrer, P.; Mayer, J. M.; Plazonnet, B.; Buri, P.; Gurny, R.; Int. J. Pharm. 1999, 180, 185

9. Borchard, G.; Adv. Drug Delivery Rev. 2001, 52, 145.

10. Paul, W.; Sharma, C. P.; STP Pharma Sciences 2000, $10,5$.

11. Felt, O.; Buri, P.; Gurny, R.; Drug Dev. Ind. Pharm. 1998, 24, 979.

12. Suh, J.-K. F.; Matthew, H. W. T.; Biomaterials 2000, 21, 2589.

13. Kumar, M. N. V. R.; React. Funct. Polym. 2000, 46, 1.

14. Mima, S.; Miya, M.; Iwamoto, R.; Yoshikawa, S.; J. Appl. Polym. Sci. 1983, 28, 1909.

15. Kubota, N.; Tatsumoto, N.; Sano, T.; Toya, K.; Carbohydr. Res. 2000, 324, 268.

16. Kurita, K.; Kamiya, M.; Nishimura, S. I.; Carbohydr. Polym. 1991, 16, 83.

17. Aiba, S. I.; Die Angewandte Makromolekulare Chemie 1993, 194, 65.

18. Kim, S. S.; Kim, S. H.; Lee, Y. M.; J. Polym. Sci., Part B: Polym. Phys. 1996, 34, 2367.

19. Zong, Z; Kimura, Y; Takahashi, M.; Yamane, H.; Polymer 2000, 41, 899.

20. Samain, E.; Chazalet, V.; Geremia, R. A.; J. Biotechnol. 1999, 72, 33.

21. Baumann, H.; Faust, V.; Carbohydr. Res. 2001, 331, 43.

22. Lillo, L. E.; Matsuhiro, B.; Carbohydr. Polym. 1997, 34, 397.

23. Senel, S.; Hincal, A.; J. Controlled Release 2001, 72, 133.

24. Sinha, V. R.; Kumria, R.; Int. J. Pharm. 2001, 224, 19.

25. Kurita, K.; Prog. Polym. Sci. 2001, 26, 1921.

26. Jagur-Grodzinski, J.; Heterogeneous Modification of Polymers - Matrix and Surface Reactions, John Wiley \& Sons: New York, 1997.

27. Vachoud, L.; Zydowicz, N.; Domard, A.; Carbohydr. Res. 1997, 302, 169.

28. Vachoud, L.; Zydowicz, N.; Domard, A.; Carbohydr. Res. 2000, 326, 295.

29. Montembault, A.; Viton, C.; Domard, A.; Biomaterials 2005, 26, 933.

30. Montembault, A.; Viton, C.; Domard, A.; Biomaterials 2005, 26, 1633.

31. Vidal, R. R. L.; Fagundes, F. P.; Menezes, S. M. C.; Ruiz, N. M. S.; Garcia, R. B.; Macromol. Symp. 2005, 229, 118.

32. Rinaudo, M.; Pavlov, G.; Desbrières, J.; Polymer 1999, 79, 7029.

33. Garcia, R. B.; Vidal, R. R. L.; Rinaudo, M.; Polímeros: Ciência e Tecnologia 2000, 10, 155.

34. Silva, S. S.; Menezes, S. M. C.; Garcia, R. B.; Eur. Polym. J. 2003, 39, 1515.

35. Aiba, S. I.; Int. J. Biol. Macromol. 1986, 8, 173.

36. Aiba, S. I.; Int. J. Biol. Macromol. 1989, 11, 249.

37. Striegel, A. M.; Carbohydr. Polym. 1997, 34, 267.

38. Hasegawa, M.; Isogai, A.; Onabe, F.; Carbohydr. Res. 1994, 262, 161.

39. Kubota, N.; Eguchi, Y.; Polym. J. 1997, 29, 123.

40. Brugnerotto, J.; Lizardi, J.; Goycoolea, F. M.; Monal, W. A.; Desbrières, J.; Rinaudo, M.; Polymer 2001, 42, 3569.

41. Shigemasa, Y.; Matsuura, H.; Sashiwa, H.; Saimoto, H.; Int. J. Biol. Macromol. 1996, 18, 237.

42. Capitani, D.; De Angelis, A. A.; Crescenzi, V.; Masci, G.; Segre, A. L.; Carbohydr. Polym. 2001, 45, 245.

43. Puttipipatkhachorn, S.; Nunthanid, J.; Yamamoto, K.; Peck, G. E.; J. Controlled Release 2001, 75, 143.

44. Monteiro, O. A. C.; Airoldi, C.; Int. J. Biol. Macromol. 1999, 26, 119.

45. Anseth, K. S.; Bowman, C. N.; Peppas, L. B.; Biomaterials 1996, 17, 1647.

46. Hirano, S.; Koide, Y.; Carbohydr. Res. 1978, 65, 166.

47. Hirano, S.; Ohe, Y.; Ono, H.; Carbohydr. Res. 1976, 47, 315.

48. Chenite, A.; Buschmann, M.; Wang, D.; Chaput, C.; Kandani, N.; Carbohydr. Polym. 2001, 46, 39.

49. Okuyama, K.; Noguchi, K.; Kanenari, M.; Egawa, T.; Osawa, K.; Ogawa, K.; Carbohydr. Polym. 2000, 41, 237. 


\section{Rosangela Balaban Garcia*, Dayse Luzia Pinheiro da Silva e Marta Costa}

Departamento de Química, Universidade Federal do Rio Grande do Norte, CP 1662, 59078-970 Natal - RN, Brasil Fernanda Nervo Raffin

Departamento de Tecnologia Farmacêutica e de Alimentos, Centro de Ciências da Saúde, Universidade Federal do Rio Grande do Norte, 59078-970 Natal - RN, Brasil

Naira Machado da Silva Ruiz

Centro de Pesquisa Leopoldo A. Miguez de Mello, CENPES, Ilha do Fundão, Quadra 7, Cidade Universitária, Rio de Janeiro - RJ, Brasil

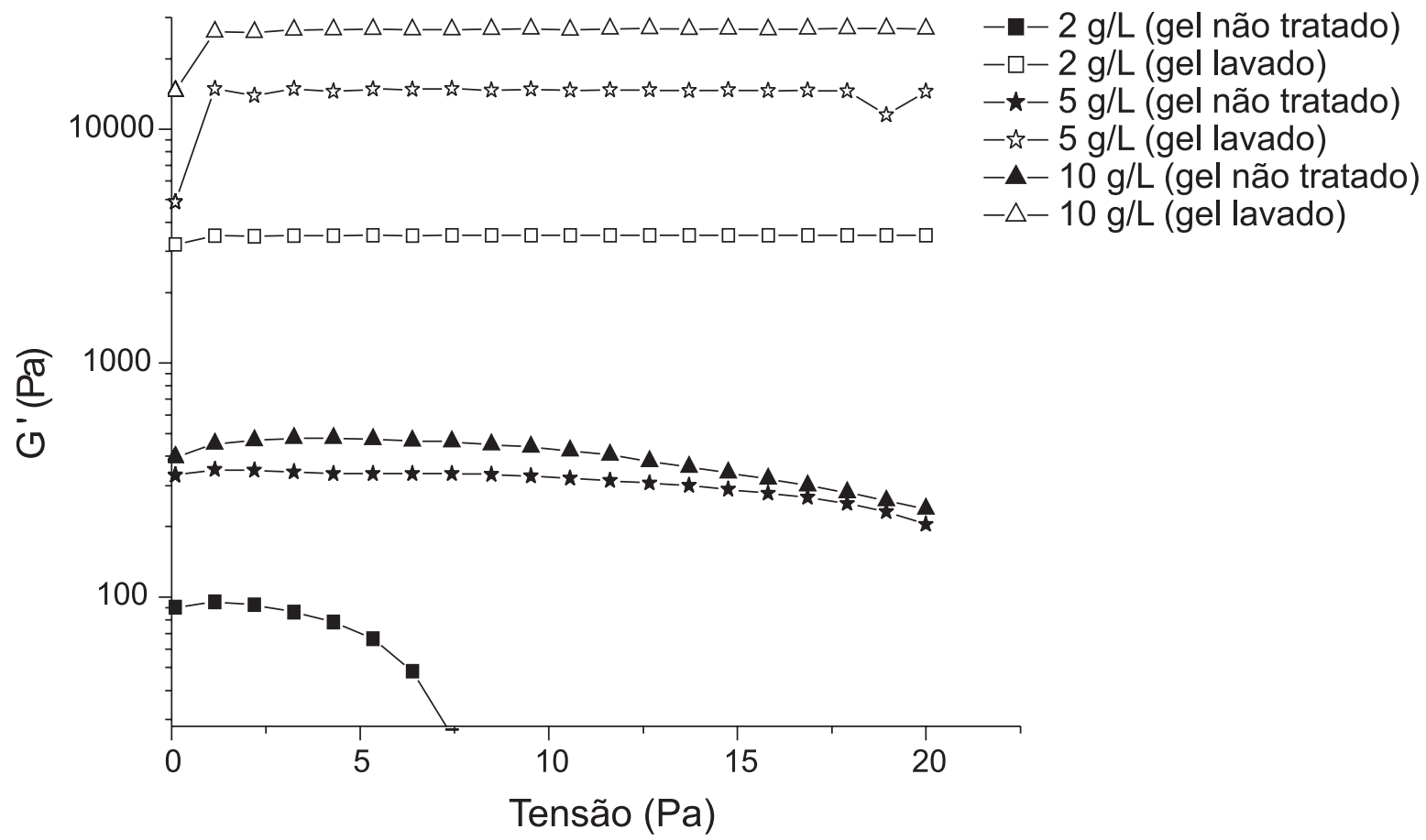

Figura 1S. Variação do módulo de estocagem $\left(G^{\prime}\right)$ em função da tensão de cisalhamento aplicada para géis de QA5, a diferentes concentrações do polímero 


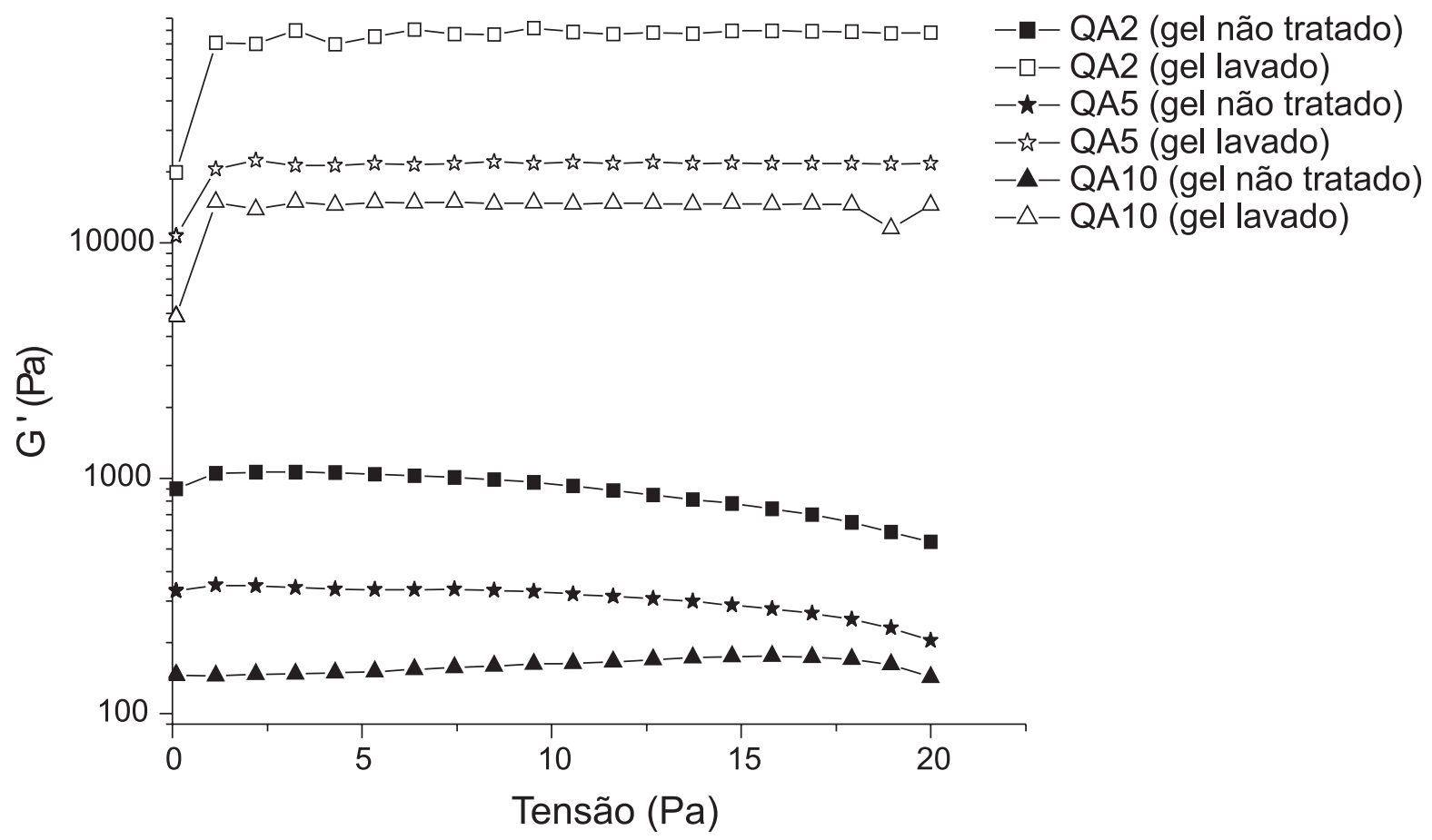

Figura 2S. Variação do módulo de estocagem $\left(G^{\prime}\right)$ em função da tensão de cisalhamento aplicada, para géis de quitosana com diferentes graus de acetilação, à concentração de $5 \mathrm{~g} / \mathrm{L}$

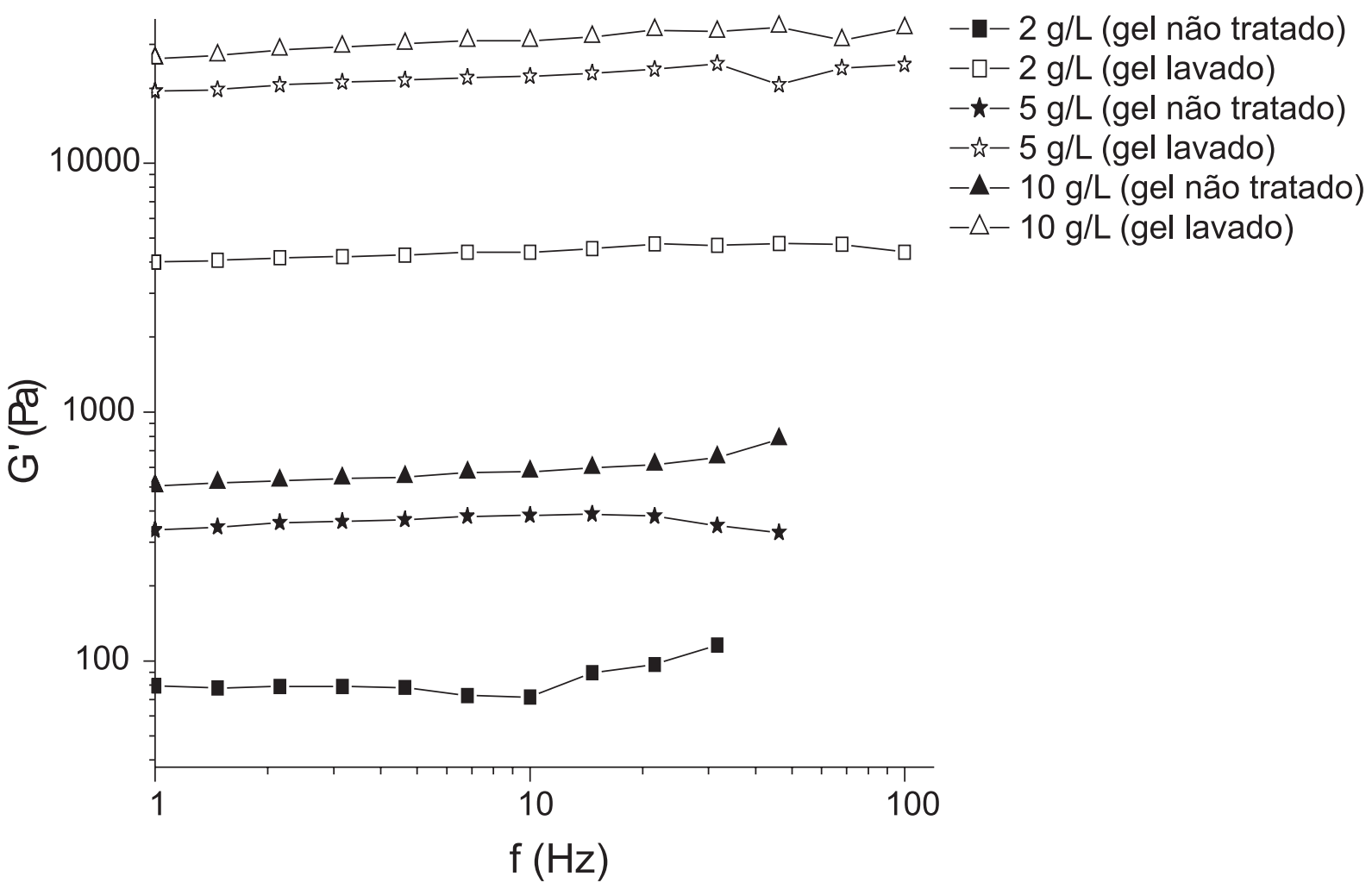

Figura 3S. Variação do módulo de estocagem $\left(G^{\prime}\right)$ em função da freqüencia de cisalhamento utilizada para géis de QA5, a diferentes concentrações do polímero 


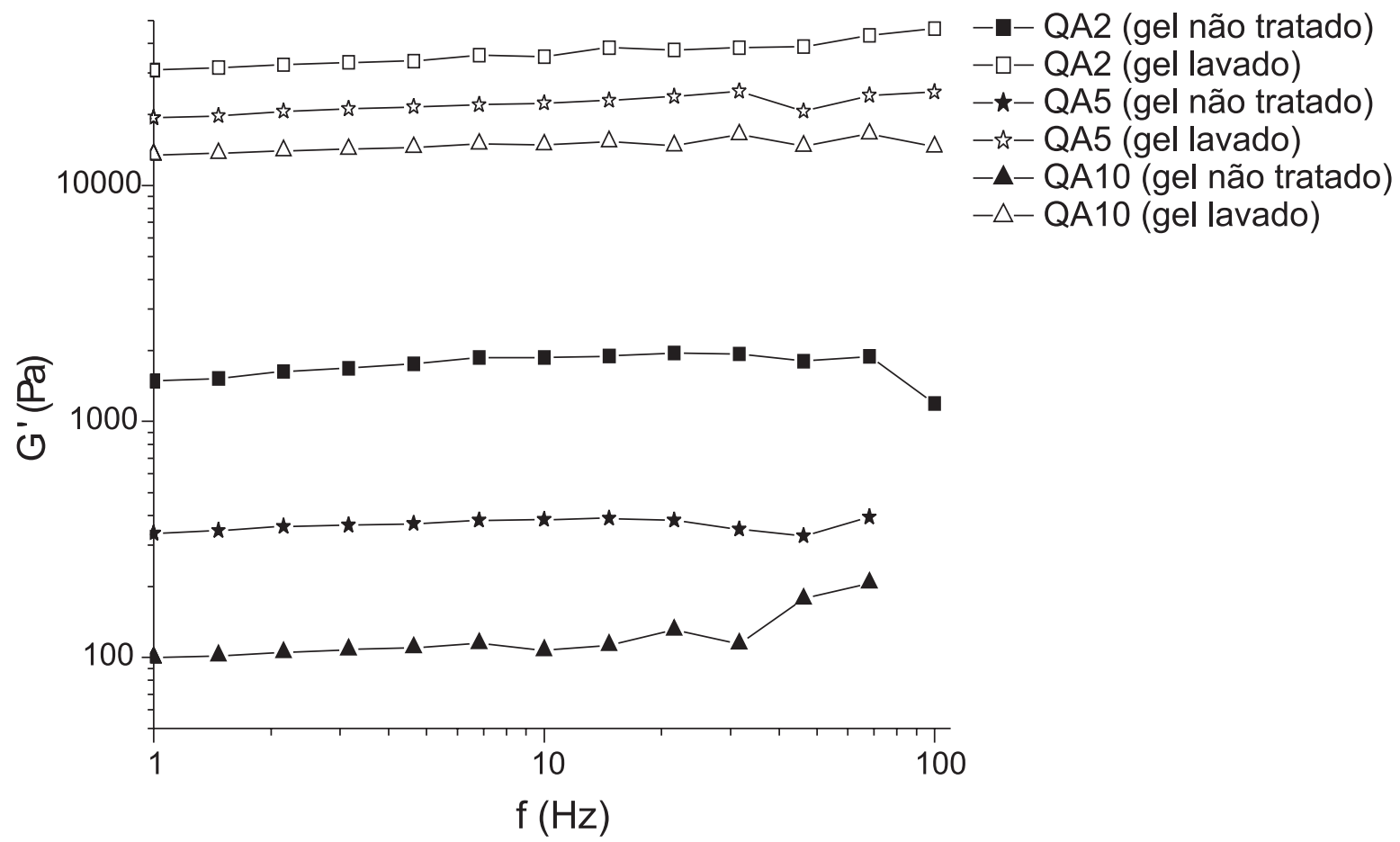

Figura 4S. Variação do módulo de estocagem $\left(G^{\prime}\right)$ em função da freqüência de cisalhamento utilizada para géis de quitosana com diferentes graus de acetilação, à concentração de polímero $5 \mathrm{~g} / \mathrm{L}$

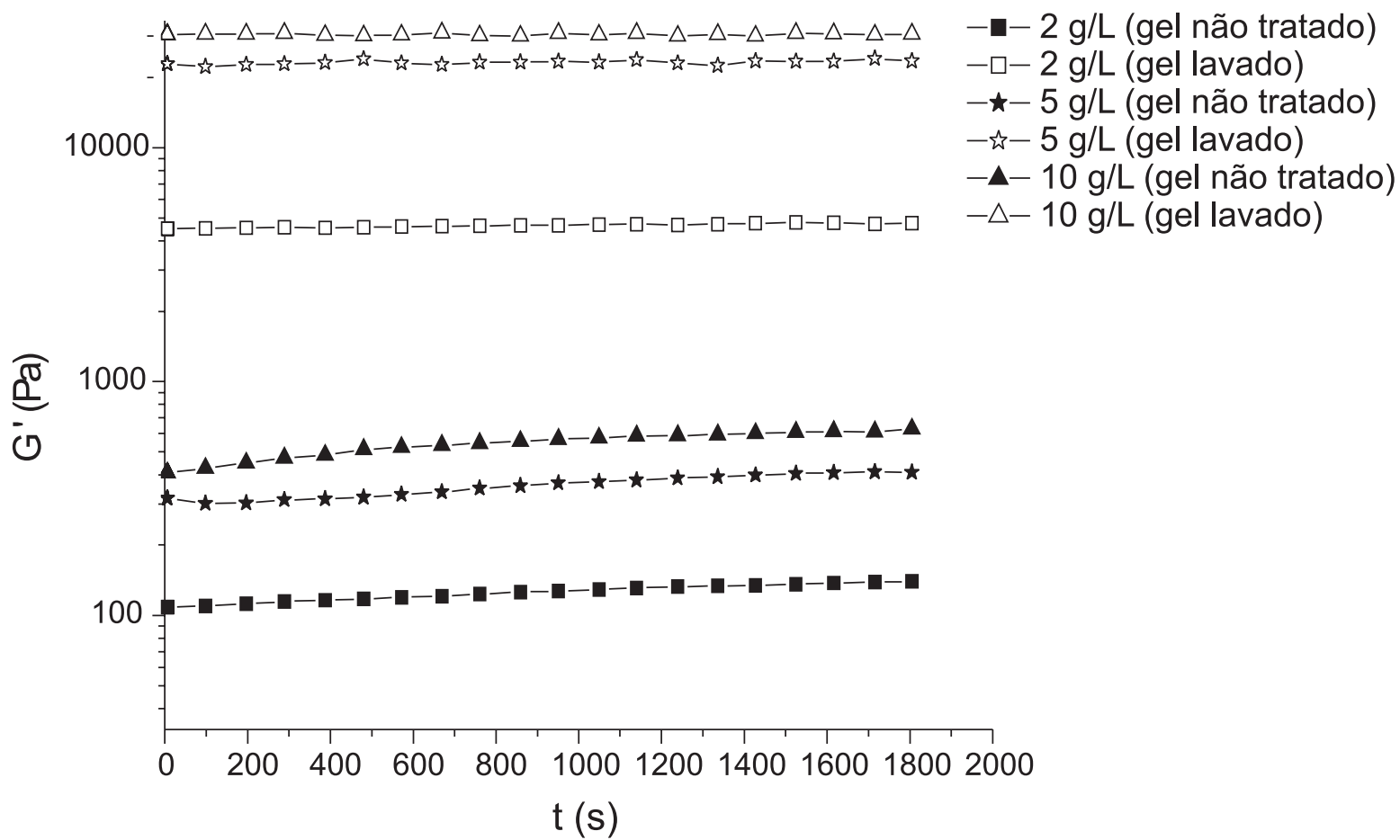

Figura 5S. Variação do módulo de estocagem $(G$ ') em função do tempo de cisalhamento para géis de QA5, a diferentes concentrações de polímero 


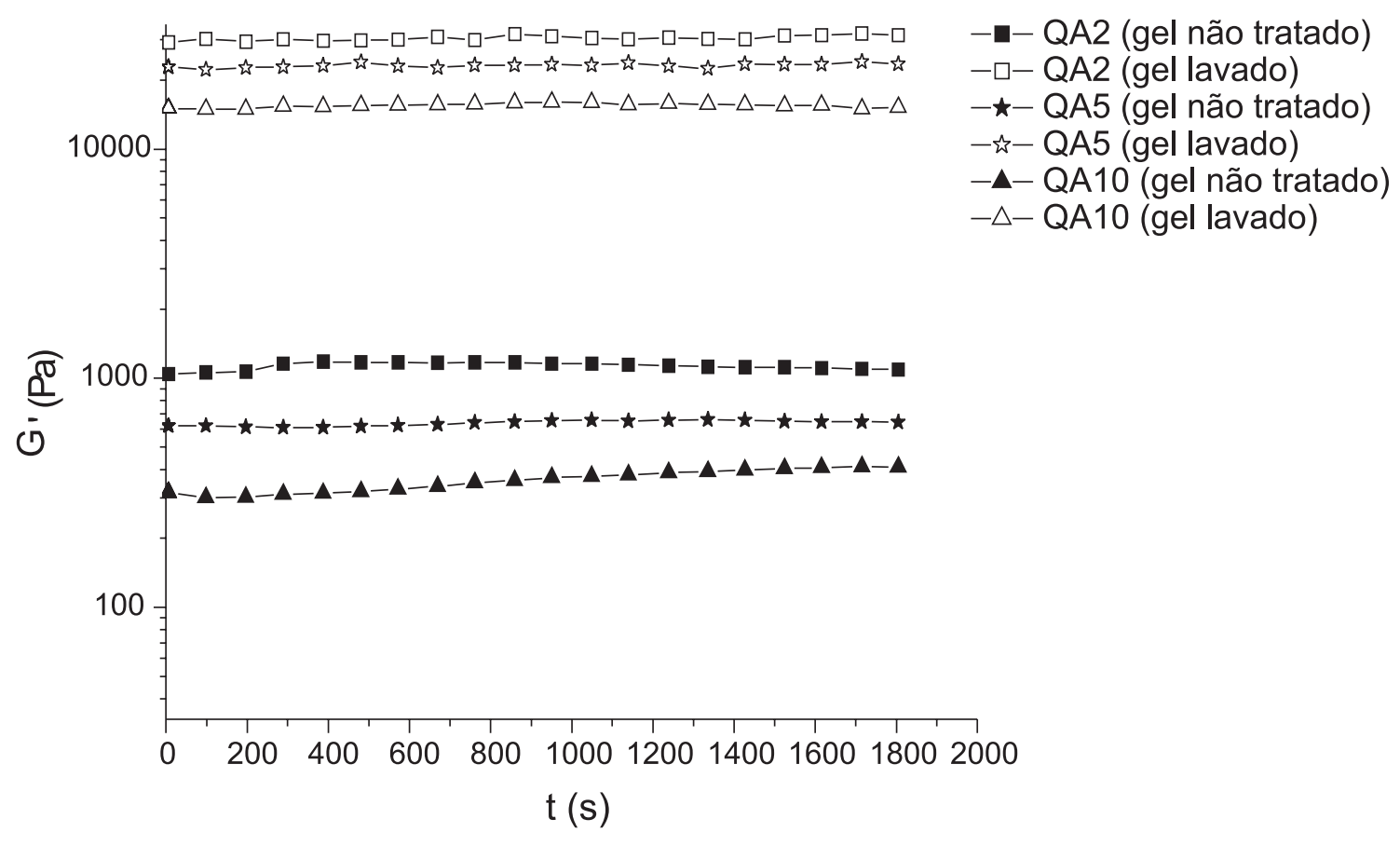

Figura 6S. Variação do módulo de estocagem $\left(G^{\prime}\right)$ em função do tempo de cisalhamento, para géis de quitosana com diferentes graus de acetilação, à concentração de $5 \mathrm{~g} / \mathrm{L}$ 

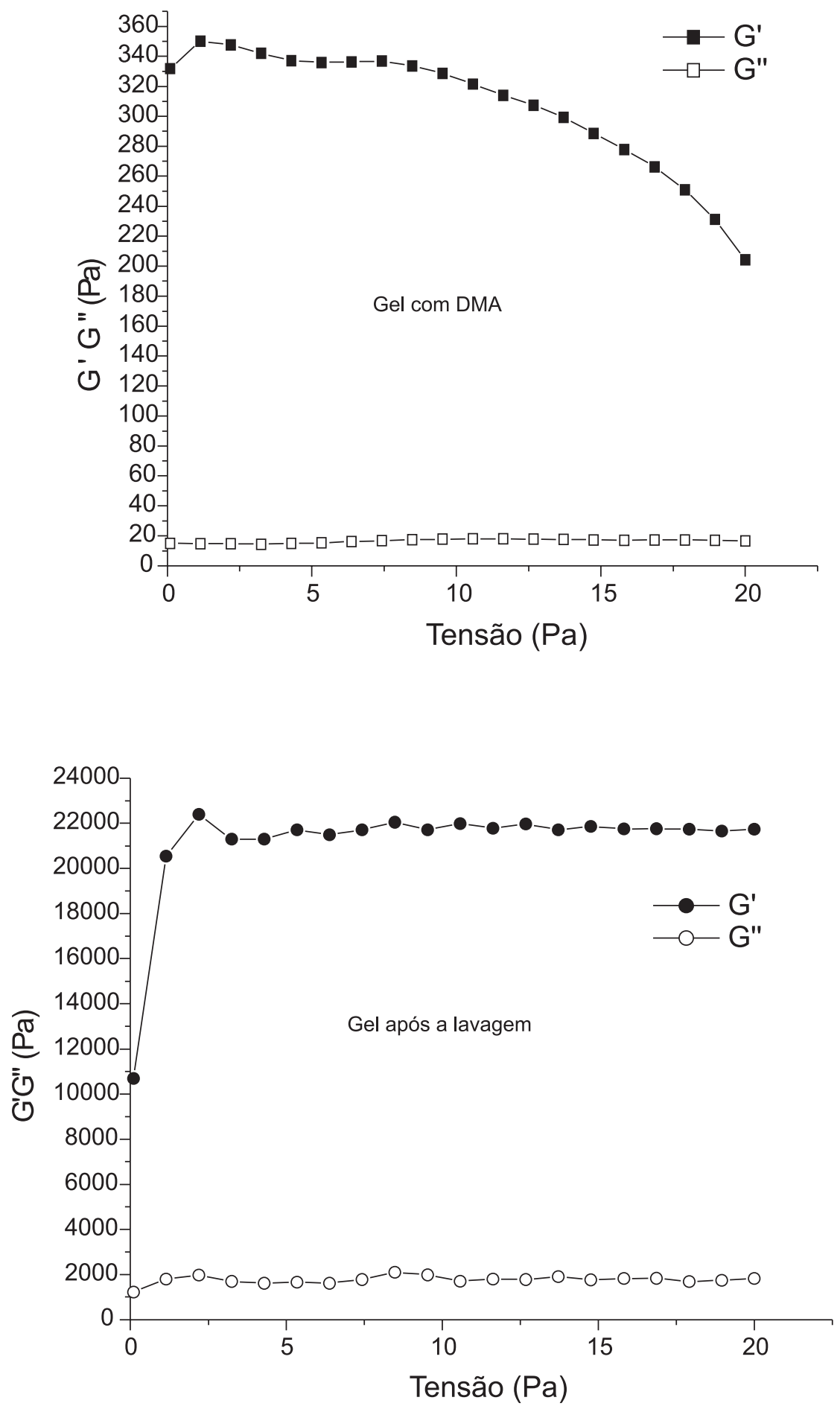

Figura 7S. Variação do módulo de estocagem $\left(G^{\prime}\right)$ e de perda $\left(G^{\prime}\right)$ em função da tensão de cisalhamento aplicada para géis de quitosana QA5, à concentração de $5 \mathrm{~g} / \mathrm{L}$ 


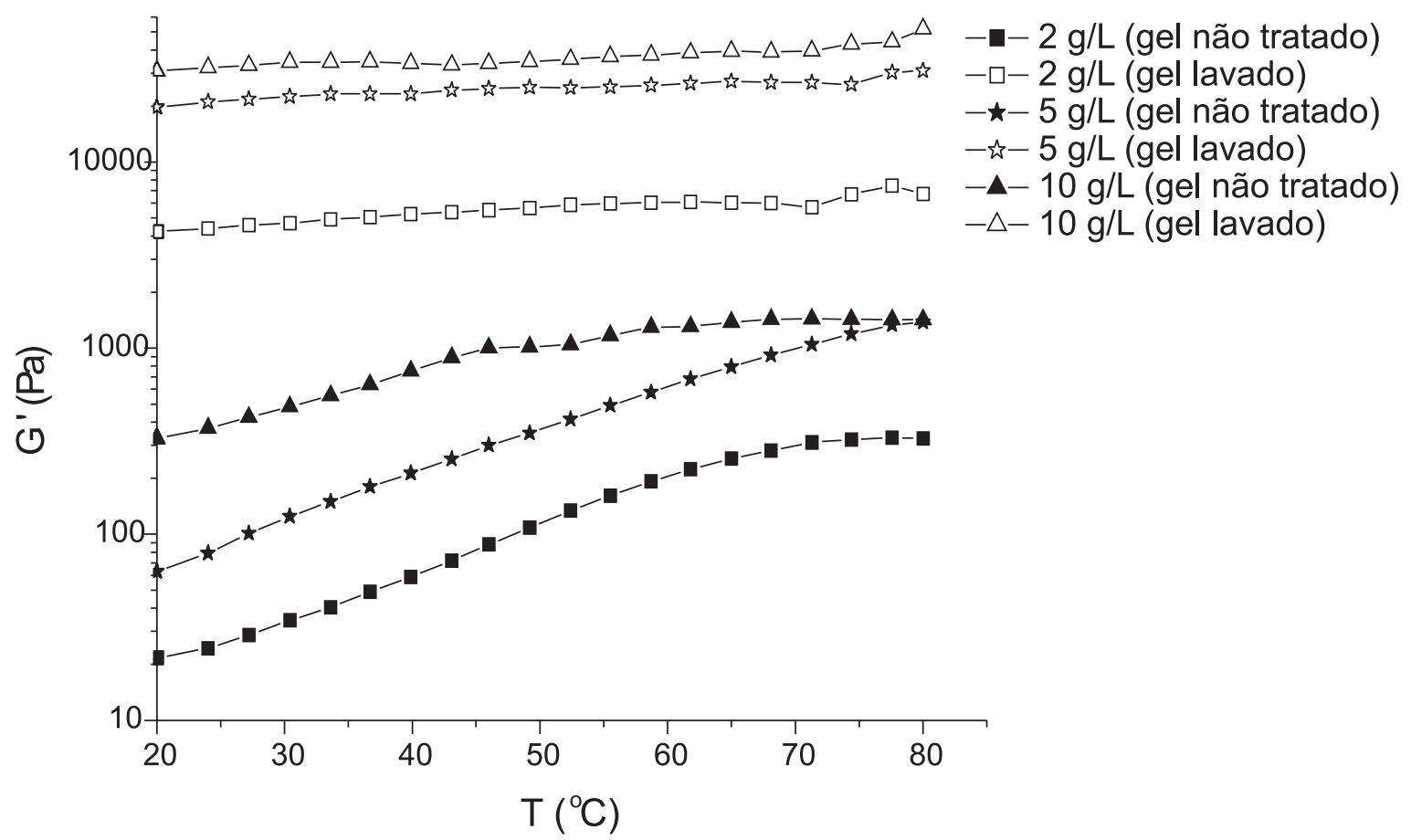

Figura 8S. Variação do módulo de estocagem $(G$ ') em função da temperatura para géis de QA5, a diferentes concentrações de polímero

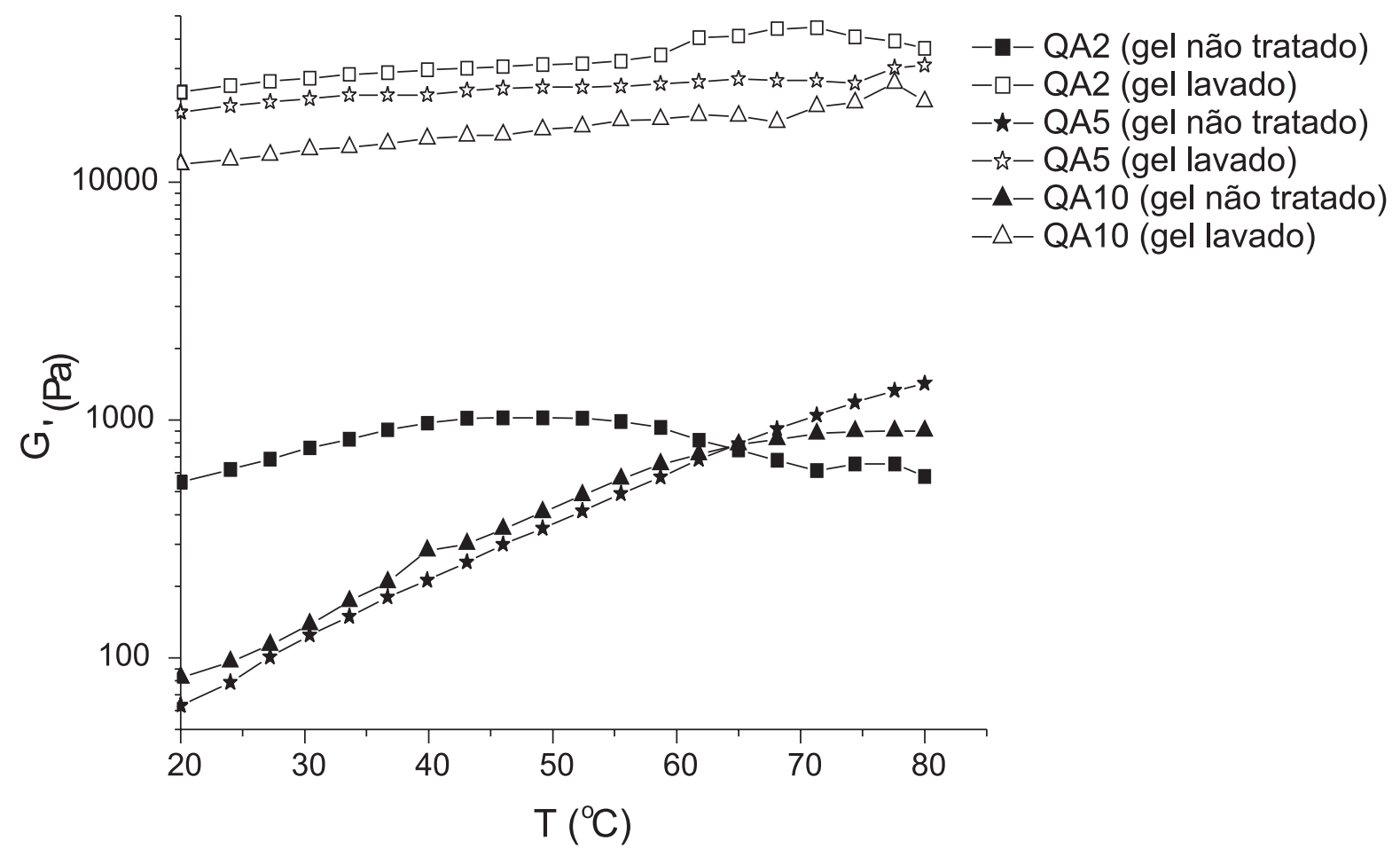

Figura 9S. Variação do módulo de estocagem $\left(G^{\prime}\right)$ em função da temperatura para géis de quitosana com diferentes graus de acetilação, à concentração de $5 \mathrm{~g} / \mathrm{L}$ 